\title{
Good Visual Acuity Outcome from an Ocular Blast Injury with Proper Management in Dr. Soetomo General Hospital Surabaya, Indonesia
}

\author{
Authors: \\ Rif'at Nurfahri*(i) \\ Delfitri Lutfi \\ Ismi Zuhria
}

Affiliations:

Department of Ophthalmology, Faculty of Medicine, Universitas Airlangga-RSUDDr. Soetomo Surabaya, Indonesia.

Corresponding author: Rif'at Nurfahri rifat.nurfahri-2019@fk.unair.ac.id

Article History:

Received: 15 July 2021

Revised: 11 September 2021

Accepted: 13 September 2021

Published: 01 November 2021

DOI:

https://doi.org/10.20473/

vsehj.v1i1.2021.1-5

\section{Copyright:}

(C) 2021 Author(s). Open access under Creative Commons Attribution-Share Alike $4.0 \quad$ International Licence (CC-BY-SA).

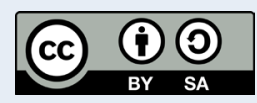

\begin{abstract}
Introduction: Ocular blast injury related to fireworks most often causing corneal erosion (29\%), conjunctival erosion (11\%), and conjunctival foreign body (10\%) with children are more often than adults (65.9\%:34.1\%), and males far more often than female (71.9\%:28.1\%). Knowing proper management is very important to achieve the best result. Case presentation: We describe an ocular blast injury that experienced broad erosion and multiple foreign bodies on the corneal and pericorneal surface in the left eye and visual acuity decreased. The foreign body was scattered, and the fluorescein test was positive. We did proper foreign body extraction, irrigation, and ocular bandage. It was treated with chloramphenicol $0.5 \%$ eye ointment and homatropine eye drop. In two months, the patient's left eye had clear cornea with a small scar formation near the visual axis. The visual acuity was $6 / 7$ and BCVA was $6 / 6$ with S- 0.5 C- 0.5 A $50^{\circ}$ correction. Conclusions: Patients with ocular blast injury limited to superficial cornea erosion and and conjunctival erosion have a reasonable probability of achieving the best visual acuity. Foreign body extraction, proper irrigation, and topical medication show promising results. Scar formation near the visual axis can disrupt visual acuity however can be corrected in this case it can be corrected with glasses. Furthermore, public promotion and regulation to control firework using are very important.
\end{abstract}

Keywords: ocular blast injury; fireworks; corneal erosion; multiple foreign bodies

\section{Introduction}

Fireworks have been commonly used worldwide as part of public festivals or entertainment for hundreds or thousands of years. Fireworks related to ocular blast injury cases increase in holidays like the new year or religious special day celebrations. ${ }^{[1]}$ In the United States, from 2000 to 2010, 97.562 blast injury cases related to fireworks have been reported in the emergency room, with head and neck injuries covered $42 \%$ of all cases. In his new report, ${ }^{[2]}$ the United States Consumer Product Safety Commission estimated that in 2017 there was 12.900 cases, 1.538 cases (12\%) were categorized as an ocular blast injury.Thirty patients with 34 eyes affected were found during Eid Al-Fitr in the East Coast Peninsula of Malaysia from $10^{\text {th }}$ September to $17^{\text {th }}$ October $2008 ; 38.24 \%$ had visual acuity outcomes worse than 6/9. ${ }^{[3]}$

Ocular blast injury related to fireworks most often causes corneal erosion(29\%), corneal punctate staining (13\%), conjunctival erosion (11\%), and conjuncitval foreign body (10\%). ${ }^{[1]}$ The child is more often than adults (65.9\%:34.1\%) and males are more often than females (71.9\%:28.1\%). ${ }^{[2]}$ Knowing proper examination and therapies is very important, especially in emergency settings, to achieve the best outcome of patient's management. It is the first case report of ocular blast injury in children in Soetomo General Hospital Surabaya in 2021 that shows clinical condition, initial management, follow-up management, and good outcome shown in the end. 


\section{Case presentation}

The patient was a nine-year-old boy from Lamongan District, and the first examination was on $14^{\text {th }}$ April 2021 in the Emergency Room (ER). Chief complaints were redness, pain, watery, blurry, and burnt sensation in the left eyelid. The patient had a history of exposure to firework blast 20 hours before he came to the hospital. After the injury, the patient rubbed his eye and irrigated with $1.5 \mathrm{~L}$ tap water. The patient went to Dr. Soegiri General Hospital Lamongan then he was referred to Dr. Soetomo General Hospital Surabaya.

Objective examination showed Glasgow Coma Score (GCS) was 456, and Visual Analogue Score (VAS) was 2-3. The right eye visual acuity examination using Snellen chart was right eye 6/6 and left eye 6/25 pinhole 6/20. The anterior segment of the right eye was within normal limit. The left eye had eyelid edema and excoriation of $20 \times 5 \mathrm{~mm}$, conjunctival and pericorneal hyperemia, and a foreign substance in the conjunctiva and cornea. Fluorescein test showed epithelial corneal erosion of $8 \mathrm{x}$ $11 \mathrm{~mm}$. Seidel test was negative while anterior chamber, iris, pupil, and lens were within the normal limit (Figure 1). Retinal reflex in both eyes was positive, the right eye was within normal limit while the left eye was difficult to be evaluated.

Patient was assessed as ocular blast injury with multiple foreign bodies and corneal erosion conjunctival and pericorneal hyperemia, eyelid excoriation of the eyelid. We have given two drops of $0.5 \%$ pantocaine eyedrop and two drops of $2 \%$ pantocaine eyedrop then extracted foreign body dust from the eyelid, conjunctiva, and cornea using wet cotton buds tip (Figure 3 ) in front of slit-lamp. The procedure was repeated several times until the superficial surface was clear. We have decided to leave the deeper foreign body in place. At last, we have irrigated the ocular surface using $500 \mathrm{ml} \mathrm{0.9 \%} \mathrm{NaCl}$. The

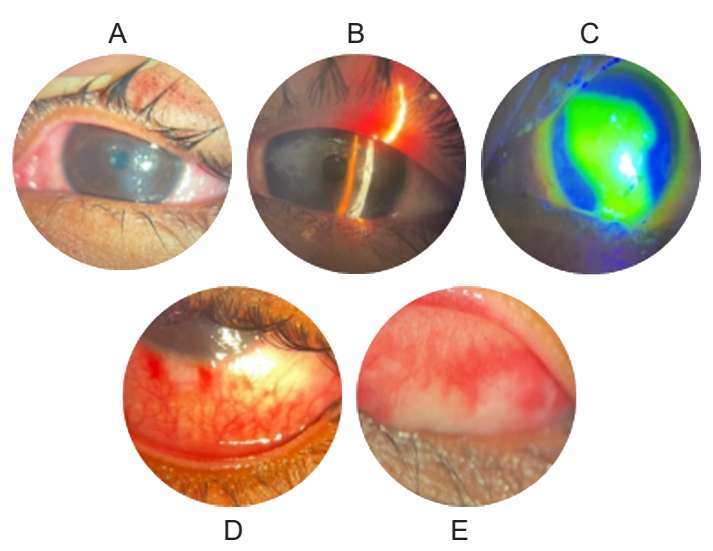

Figure 1. Anterior segment of the left eye; (A) Excoriation, conjunctival and pericorneal hyperemia, multiple erosion in the corneal surface; (B) Epithelial depth erosion from the slit-lamp examination; (C) Positive fluorescein test of $8 \times 11 \mathrm{~mm}$; (D) Conjunctival hyperemia and foreign body; (E) Pars palpebral conjunctival hyperemia.

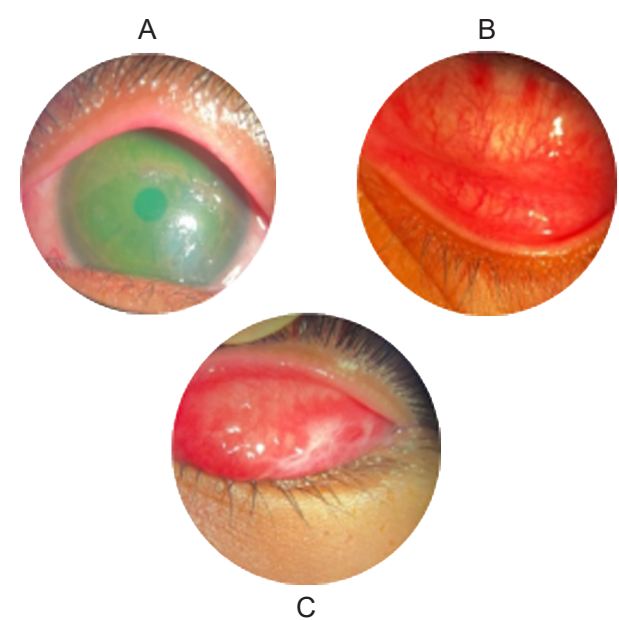

Figure 2. Clinical presentation after extraction; (A) Clear corneal surface without foreign body, positive erosion; (B) Conjunctival hyperemia, without foreign body; (C) Conjunctival hyperemia in upper eyelid, without foreign body.

patient has been given chloramphenicol eye ointment every eight hours one drop cycloplegic homatropine eyedrop every 12 hours and eye patch. The patient will be evaluated the next day in the clinic. The final examination clinical presentation is shown in Figure 2.

On the next day, the patient still experienced mild watery and discomfort eyes. Physical examination revealed left eye visual acuity was 6/12 pinhole 6/10, minimal eyelid swelling and spasm, positive excoriation, conjunctival and pericorneal hyperemia, corneal erosion with positive fluorescein test of $8 \times 11 \mathrm{~mm}$ (Figure 4). The patient has been given chloramphenicol eye ointment every eight hours, homatropine eyedrop every 12 hours, and artificial tear every four hours and was planned for following observation in the next 2-3 weeks.

At the subsequent examination, the patient did not have any complaints. The visual acuity was $6 / 7.5$ pinhole $6 / 6$, normal eyelid, negative hyperemi, 2 x $2 \mathrm{~mm}$ inferior corneal scar formation near to visual axis and negative fluorescein test (Figure 5). Posterior segment of both eyes was within normal limit. The patient has been given artificial tear every four hours. Education about eyelid hygiene with the next follow up in 2-3 weeks. Six weeks after the injury, the patient did not have any complaints. Visual acuity was 6/7.5 with correction S-0.50 C-0.50 axis $50^{\circ}$ became $6 / 6$. The clinical presentation is shown in Figure 6, and the patient was prescribed glasses.

\section{Discussion and conclusions}

Blast injury is a complex event and has a direct and indirect pathway to cause damage. It can be from industrial components, recreational like fireworks, or warfare tools. In the past, blast injury was dominated by war causes, but today domestic cause is the primary cause. ${ }^{[4]}$ History taking is essential to understand the mechanism of injury. 


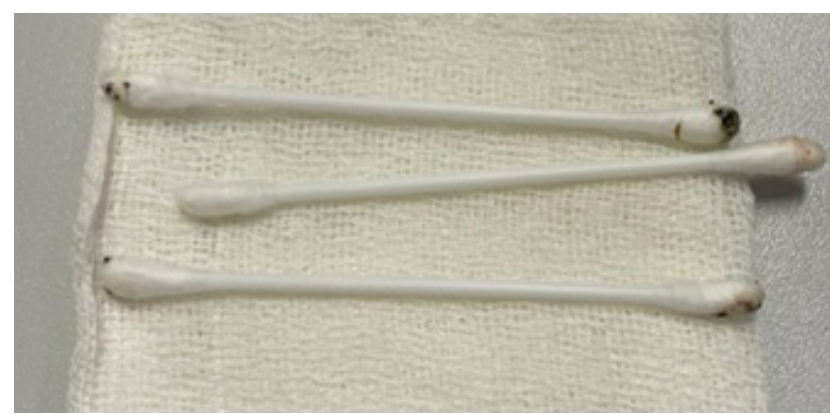

Figure 3. Wet cotton bud with black foreign body dust after extraction.

Shape, size, the proximity of the point of impact to the globe, energy, and angle of incidence are essential factors in the mechanism of injury. ${ }^{[5]}$ Young and middle-aged males ( $22 \pm 13$ years) most widely affected compared to females even experienced more devastating damage. The dominant male role in using or manufacturing fireworks and other prone to explode components is the leading cause of this condition. ${ }^{[1]}$ This case report also happened in the male patient.

Blast injury has four categories of trauma mechanism, primary, secondary, tertiary, and quarter. Primary is the blast's direct force that hits the body. Secondary is fragment things thrown by blast that hit the body. Tertiary is blast force with body damaged. The quarter is every damage uncategorized to primary, secondary, or tertiary. ${ }^{[4]}$ From the clinical examination, we categorized this patient's injury as primary and secondary mechanisms.

We present a case report about multiple foreign bodies with corneal erosion, pericorneal hyperemia, and excoriation in the eyelid caused by firework blast. Corneal foreign bodies are usually associated with immediate pain, foreign-body sensation, tearing, and discomfort. The presence, extent, and depth of the corneal defect can be determined using slit-lamp examination. The fluorescein test is beneficial in diagnosing foreign body and epithelial

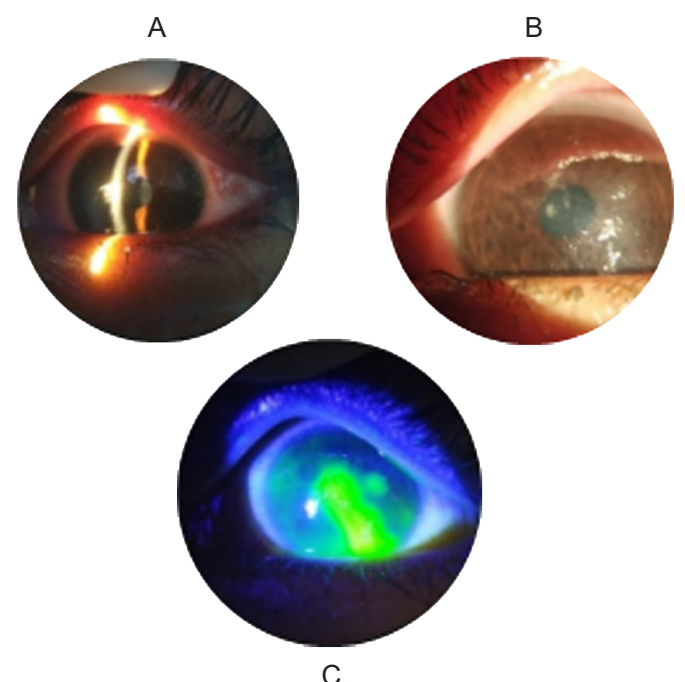

Figure 4. Clinical presentation two days after injury; (A) Slit lamp shows epithelial depth corneal erosion; (B) Corneal erosion at central and epicentral; (C) Fluorescein test positive. defects of the cornea. Conjunctival foreign bodies are best recognized by the slit-lamp examination with eyelid eversion. ${ }^{[8]}$ In this case, a foreign body in conjunctiva and cornea were found on slit-lamp examination and fluorescein test examination.

In patients with blast injuries, all possible foreign bodies on or near the cornea's surface should be meticulously extracted to prevent subsequent erosion of the superficial foreign bodies. A cotton-tipped applicator moistened with topical anesthetic can be used as in this case. Double eversion of the eyelid allows complete examination. Irrigation using $\mathrm{NaCl} 0.9 \%$ to cleans the fornix and cornea must be done until no residual foreign body is found. After removing corneal foreign body, therapy includes topical antibiotic, cycloplegia, and occasionally applying a firm pressure patch should be performed. Topical antibiotic ointment is suggested in corneal abrasion. Cycloplegics can prevent ciliary spasm associated with corneal abrasion. ${ }^{[8]}$ Non-Steroid Anti Inflammatory Drugs (NSAIDs) ${ }^{[6]}$ should be given in cases of pain. There is no evidence that topical NSAIDs are better than oral NSAIDs. Topical anesthetic drops can safely be used at low concentrations for short periods. Overuse and unsupervised topical anesthetic exert toxic effects that delay corneal healing. Ice or cold pack can be the alternative option for analgesia. ${ }^{[9]}$ Eye patching for corneal abrasion can alleviate some degree of pain, even though some studies show no significant difference between patching and non-patching groups. ${ }^{[10]}$
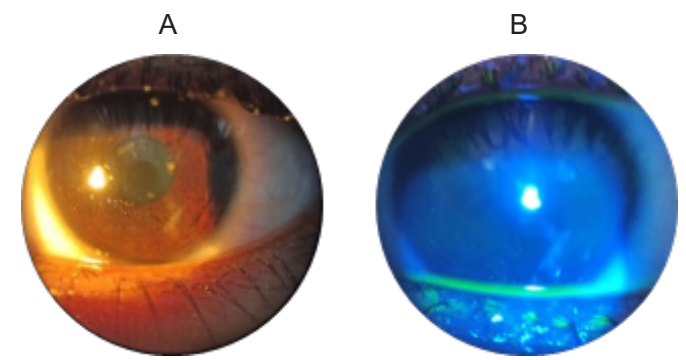

Figure 5. Clinical presentation three weeks after injury; (A) Scar formation near the visual axis; (B) Negative fluorescein test.

The cornea is the outer anterior casing of the eye and protects the inner portion from the external environment. The cornea, also the most potent focusing element, provides about $80 \%$ refractive power of the eye. ${ }^{[11]}$ The cornea consists of five layers; the outermost layer is the pain-sensitive epithelial layer because it has many innervations. The epithelial layer consists of 4-6 layers 200-300 $\mu \mathrm{m}$ thick. It has three cells component that are squamous cell, wing cell, and basal epithelial cell with tight junction to prevent exogenous infiltration. ${ }^{[12]}$ Epithelial cells have an age duration of 7-10 days, fastest among corneal layers. ${ }^{[13]}$ Some scar formation always occurs in foreign bodies that entering the corneal 


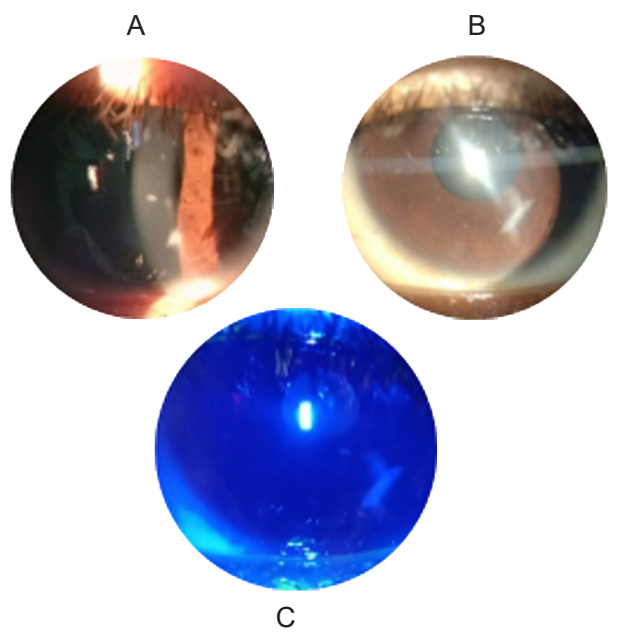

Figure 6. Clinical presentation in last follow up; (A) Some degree of scar formation; (B) Broad beam showed scar formation;(C) Negative fluorescein test.

stroma deeply to the Bowman layer. Stromal injury may induce secretion of proinflammatory and profibrotic cytokines such as IL-1, TNF-, and MCP-1 that contribute to extracellular matrix remodeling and scar formation. ${ }^{[14]}$ Scar formation in the visual axis may result in glare and vision decreased with irregular astigmatism. ${ }^{[8]}$ In this case, corneal erosion in the left eye has disappeared three weeks after the initial accident. Scar formation was found in inferior cornea near the visual axis causing visual acuity disturbance.The patient can get normal vision using glasses.

Firework bans have been recommended worldwide by The World Health Organization (WHO) ${ }^{[2]}$ since 1984 and the effectivity of this ban is well presented in the USA. States without restricting fireworks regulation have an incidence of blast injury ten times bigger than those with regulation. Fireworks ban in Norway in 2008 significantly reduced firework-related eye injuries by half compared with the mean incidence in 2005-2007 when the firework is allowed. ${ }^{[15]}$ The lifting of restrictive fireworks law in North Ireland is followed by the threefold increase of firework-related ocular injury. ${ }^{[16]}$

Patients with ocular blast injury limited to superficial erosion of cornea and conjunctiva have a reasonable probability of achieving the best visual acuity. Foreign body extraction, proper irrigation, and topical medication have shown promising results. Scar formation near the visual axis can disrupt visual acuity but can be corrected with glasses. Furthermore, the public promotion that fireworks can cause blast injury to the cornea and regulation to control firework using is essential.

\section{References}

[1] Frimmel S, de Faber JT, Wubbels RJ, Kniestedt C, Paridaens D. Type, severity, management and outcome of ocular and adnexal firework-related injuries: The Rotterdam experience. Acta Ophthalomologica 2018;96:607-615. https://doi.org/10.1111/aos.13711.
[2] Shiuey EJ, Kolomeyer AM, Kolomeyer NN. Assessment of firework-related ocular injury in the US. JAMA Ophthalmol 2020;138:618-623. https://doi.org/10.1001/ jamaophthalmol.2020.0832.

[3] Rashid RA, Heidary F, Hussein A, Hitam WHW, Rashid RA, Ghani ZA, et al. Ocular burns and related injuries due to fireworks during the Aidil Fitri celebration on the East Coast of the Peninsular Malaysia. Burns 2011;37:170-173. https://doi.org/10.1016/j.burns.2010.05.019.

[4] Yu M, Lv Q, Ding H, Zeng X, Cao J, Liu J, et al. Evaluation of blast injury patients from the 2015 Tianjin explosions in China. Burns 2016;42:1133-1140. https://doi.org/10.1016/j. burns.2016.03.004.

[5] Criden MR, Katz SE, Lembach RG. Corneal and Conjunctival Foreign Bodies No Title. In: Brightbill F, McDonnell P, McGhee C, Farjo A, Serdarevic O, editors. Corneal Surg. Theory Tech. Tissue. 4th ed., Missouri: Mosby Elsevier; 2009, p. 133-138.

[6] Wakai A, Lawrenson JG, Lawrenson AL, Wang Y, Brown MD, Quirke $M$, et al. Topical non-steroidal anti-inflammatory drugs for analgesia in traumatic corneal abrasions. Cochrane Database Syst Rev 2017;5:CD009781. https://doi. org/10.1002/14651858.CD009781.pub2.

[7] Lin Y, Liang X, Liu X, Qu B, Ni Y, Jiang S, et al. Prognostic factors and visual outcome for fireworks-related burns during spring festival in South China. J Burn Care Res Off Publ Am Burn Assoc 2012;33:e108-e113. https://doi. org/10.1097/BCR.0b013e3182335998.

[8] Weisenthal RW, Daly MK, de Freitas D, Feder RS, Orlin SE, Tu EY, et al., editors. Clinical Aspects of Toxic and Traumatic Injuries of the Anterior Segment. Extern. Dis. Cornea 2019-2020 Basic Clin. Sci. Course, San Fransisco: American Academy of Ophthalmology; 2019, p. 375-410

[9] Fraser R, Walland M, Chan E, Crock C. Topical anaesthetic in the treatment of corneal epithelial defects: What are the risks? Aust J Gen Pract 2019;48:504-506. https://doi. org/10.31128/AJGP-09-18-4709.

[10] Lim CHL, Turner A, Lim BX. Patching for corneal abrasion. Cochrane Database Syst Rev 2016;7:CD004764. https://doi. org/10.1002/14651858.CD004764.pub3.

[11] Mobaraki M, Abbasi R, Omidian Vandchali S, Ghaffari M, Moztarzadeh F, Mozafari M. Corneal repair and regeneration: Current concepts and future directions. Front Bioeng Biotechnol 2019;7:135. https://doi.org/10.3389/ fbioe.2019.00135.

[12] Gonzales-Andrades M, Argüeso P, Gipson I. Corneal Anatomy. In: Alio JL, del Barrio JLA, Arnalich-Montiel F, editors. Corneal Regen. Ther. Surg., Switzerland: Springer; 2019, p. 3-12.

[13] Vargas V, Arnalich-Montiel F, del Barrio JLA. Corneal Healing. In: Alio JL, del Barrio JLA, Arnalich-Montiel F, editors. Corneal Regen. Ther. Surg., Switzerland: Springer; 2019, p. 13-22. 
[14] Ljubimov A V, Saghizadeh M. Progress in corneal wound healing. Prog Retin Eye Res 2015;49:17-45. https://doi. org/10.1016/j.preteyeres.2015.07.002.

[15] Bull N. Legislation as a tool to prevent firework-related eye injuries. Acta Ophthalmol 2011;89:e654-e655. https://doi. org/10.1111/j.1755-3768.2010.02061.x.

[16] Wisse RPL, Bijlsma WR, Stilma JS. Ocular firework trauma: A systematic review on incidence, severity, outcome and prevention. Br J Ophthalmol 2010;94:1586-1591. https:// doi.org/10.1136/bjo.2009.168419. 